Timothy McIntyre, THE UNIVERSITYOF QUEENSLAND, t.mcintyre@uq.edu.au

\title{
Dynamic e-learning modules for student lecture preparation
}

\begin{abstract}
We have developed and demonstrated the effectiveness of a set of online interactive learning modules to accompany physics courses at first- and second-year university levels. Students access the modules prior to attending lectures to familiarize themselves with content which is then discussed and reaffirmed in class. Student surveys and access data show that students were much more likely to use material presented in this form, rather than a textbook, when preparing for lectures given in an active learning format. The students found that interactive simulations, videos of problem-solving approaches prepared by course staff, and quick-check immediate feedback questions were all useful tools for lecture preparation-none of which are available when using a traditional textbook for lecture preparation.
\end{abstract}

\section{KEYWORDS}

active learning, simulations, lecture preparation, online learning

The approach to teaching physics and other related subjects at university level has evolved greatly in recent years. Particularly since Hake's foundational paper on active engagement compared with traditional passive lectures of formal 'chalk-and-talk' (Hake, 1998), classes are now commonly interactive with students expected to prepare (and learn content) prior to attending. Various styles of this learning method exist, all aimed at promoting active engagement with course content during class. An early innovator and popularizer of active learning in Physics, and then elsewhere, was Mazur with his 'Peer Instruction' approach (Mazur, 2004). Students prepare for class by reading prescribed sections of a textbook and responding to reflection questions, and then lecture classes consist mainly of discussion and multiple-choice conceptual questions facilitated using electronic feedback devices.

In undergraduate physics classes at the University of Queensland we have adopted an approach similar to the style proposed by Mazur. Formal lectures have been replaced by interactive classes in which students discuss concepts, practise implementing target knowledge, and provide feedback. We use electronic polling devices ('clickers') for students to vote on the answers to multiple-choice concept questions, sometimes after group discussion. Teaching staff provide added guidance on aspects of the material that students are thereby known to have difficulties in understanding, and some problem solving is done. Students are required to prepare for these classes by reading prescribed material covering the core content of the class. However, convincing students to prepare for classes by completing a reading is a known issue, across disciplines (McMullen, 2013; Phillips \& Phillips, 2007). Our experiences show that students can be less than willing to engage in pre-lecture reading of a textbook. When we introduced this teaching style in a first-year introductory physics class, only around $30 \%$ of students reported (via anonymous in-class surveys) that they regularly completed the prescribed 
reading. We have since investigated several approaches to encourage students to complete the pre-class reading, including online reading quizzes submitted by the morning of each lecture, and in-class assessable multiple-choice questions (facilitated by the use of clickers). The latter approach led to an increase in the level of participation to about $50 \%$ of the class, but this is still far short of what we consider acceptable for effective use of the desired teaching strategy.

To overcome the limited preparedness of students for classes, we have established an alternative approach to support students' preparation. We have developed a series of online interactive e-learning modules to supply core course content for each lecture. We have been influenced by five main factors in developing these modules:

- Our students' propensity for using online media, their desire for mobile-accessible content, and their use of technology that supports mobile access to online media.

- Providing access as much as possible anytime and anywhere, to support busy mobile students.

- A commitment to engaging, active learning, and providing interactivity for students where possible to enhance learning.

- Developing materials that support the cognitive processes of learning (Clark \& Harrelson, 2002; Bransford, Brown \& Cocking, 1999).

- Using new technology that enables us to achieve these goals faster, cheaper, and more effectively.

Increasing students' access to learning resources across space and time is an ongoing goal for higher education. Today's students gain information primarily by using technology-visiting websites, watching videos online, and sharing links using social networks (Kennedy, Dalgarno, Bennett, Judd, Gray \& Waycott, 2008). At our institution, more than $90 \%$ of students own portable devices such as smartphones and tablets that can connect to online resources at home, on campus, and on the move, reflecting international trends (deNoyelles \& Seilhamer, 2013). This proliferation of smart mobile devices is offering new ways to deliver content to students when and where they find an opportunity to study. Providing content in chunks to suit these time portions increases the opportunities students have to engage effectively in preparation for class.

The dynamic nature of Physics makes it well-suited to using the technological capability of simulation to enhance learning. Physics has a strong history of developing effective interactive simulations to support students' understanding of physical models: for example, "Physics Education Technology" (PhET) simulations (Wieman, Adams \& Perkins, 2008), Physlets (Christian, 2015), our own simulations (McGrath, Wegener, McIntyre, Savage \& Williamson, 2010, SciMS, 2017), and short multimedia presentations that include animations (Wolfe, 2015).

In the electronic/online domain, video has become a key focus of education through the growth of phenomena such as Khan Academy, the flipped classrooms movement, and MOOCs (Massive Open Online Courses). In the Flipped Classroom approach (Lage, Platt \& Treglia, 2000; Educause, 2013), students typically prepare for lectures by viewing videos of the content, and classes involve students attempting to solve problems, discussing concepts, and working on projects assisted by academic staff. This gives opportunity for one-on-one interactions between staff and students. MOOCs and the associated possibilities of their development became a catchphrase across much of the university sector (Friedman, 2013; Mangan, 2012). However, MOOCs are often limited in their use of advances in 
pedagogy (Head, 2013), with many relying on electronically-delivered content being passively viewed by students (Lodge, 2013).

Our approach has been to blend online and face-to-face experiences with interaction important in both. We have developed suites of online modules, with each module designed to supply content for a single one-hour lecture. The modules, entitled Five-Minute Physics (5MP) are openly available online ("Five Minute Physics," 2017). The modules consist of text and images (static material as in a textbook), and dynamic components such as interactive simulations, short videos, and multiple-choice questions with instant feedback. These modules have been tested in a first-year algebra-based introductory physics course and a core second-year course on fields in physics. Development and implementation of the modules occurred over a number of semesters, with concurrent evaluation involving student feedback (including comparison with textbook readings) and monitoring use of the resources. We have continued to use, expand and evaluate the modules over a number of years. We have also attempted to establish the scalability and transferability of the approach-the feasibility for academic staff with limited resources to develop material of this type for their own courses.

\section{METHODOLOGY AND IMPLEMENTATION}

Our goal of developing and making widely available dynamic, interactive material in electronic format prompted considerations of technology, contributions of the development team, design philosophy, and evaluation opportunities.

We investigated the software approaches of 'apps', hybrid app development software such as PhoneGap ("PhoneGap," 2014) and web-based material. The latter approach appeared to best fulfill our students' requirements and hence was selected for our implementation. However, a persistent issue with developing web-based material is the variety of platforms and web-browsers. It can be a challenging exercise to design a webpage that appears similar and functions properly in all browsers-especially for an academic not highly experienced in web development. Some standardization has been achieved by the introduction of the Hypertext Markup Language revision 5 (HTML5). Along with cascading style sheets (CSS) and the Javascript programming language, this allows a developer to design web pages that include text, images, video, and simulations. More importantly, this format is recognized by (almost) all web browsers and functions on all current platforms (computers, tablet devices and mobile phones). This eliminates the need to develop individual 'apps' for each platform. Creating these pages is relatively straightforward-a commercial text editing package can be used for much of the development, while some programming skill is required to create interactive simulations.

Two significantly different teaching settings were used. Our primary implementation was for an introductory first-year physics class designed for students with a biological background. The course assumes no background knowledge of physics and typically has a class size of several hundred students per semester. Two of the authors (TJM, MJW) have extensive experience with teaching the course. It runs over a 13-week semester with three one-hour lecture classes and one tutorial per week. There are also laboratory sessions held generally once every two weeks. The course has used a textbook that is a required resource. Between 2009 and the first semester of 2012, students were given a prescribed reading from the textbook prior to each class. From 2011 this was assessed by an in-class multiple-choice reading question using electronic feedback devices.

In Semester 2, 2012, we piloted the first of our online modules, initially in the form of an 'app' for various mobile phone platforms. In Semester 1, 2013, we converted to using HTML5-based material and designed and created nine online pre-reading modules which were linked to certain topics in the course (mostly mechanics). In Semester 2, 2013, this was expanded to 35 modules covering the entire 
course content (replacing the textbook readings) including mechanics, thermodynamics, fluids, and biomedical applications. We have continued to use and develop these modules for lecture preparation in the course ever since.

We also prepared modules for use in a second-year core physics course on fields in physics. This course is taken by about 70 students; most of them are enrolled in either a Physics or a Mathematics major. Weekly contact sessions include a two-hour lecture class and a one-hour tutorial. Students spend about four afternoons during the semester completing laboratory experiments. A prescribed textbook was also used in this course. One author (TJM) has taught the course for several years. Three modules were initially developed covering the sections of the course on polarization, interference, and optical cavities. A full set of modules for the course was developed in 2014 and these have now been used for several years, fully replacing the textbook.

Our modules were created by a team that included a graphic designer, an experienced programmer and academic staff (including authors on this paper). Internal university funding enabled us to employ a number of research assistants who aided in developing the content. We also offered projects to final-year undergraduates who worked on developing particular aspects of the modules such as videos and simulations. The programmer created a template for the modules and established online analytics for monitoring access and usage of the modules. The graphic designer established the general appearance of the modules (in a form consistent with our university's requirements).

A general design philosophy drove the development approach. The aim of this material is to introduce students to the fundamentals of content. 5MP concentrates on core concepts and techniques, bringing all relevant material to one easily accessed location. The purpose of the textbook in our course has now changed from preparation to reference. The style of 5MP is succinct and relatively informal (conversational). Each module is clearly separated into sections, and students can work their way through these segments as time permits. Each module incorporates a number of different styles of components. The specifics of the development approach for each of these are discussed below.

Text and images are primarily used to develop the core content as in a textbook. A list of relevant sections of the textbook is included in each module as a reference. This static material has been augmented in a number of ways making use of the benefits available in an electronic implementation.

Short videos were prepared by academic staff using desktop computers and freely available recording and editing software. Video content generally consists of a staff member explaining some aspect of the content or showing how to solve a problem. This reproduces the intimacy of Khan Academy ("Khan Academy," 2015) through drawing/writing with voiceover.

Interactive simulations were written by one of the staff members (TJM) and research assistants who have previous experience in developing such simulations. This was one of the more timeconsuming aspects in preparing the pages. Simulations were created to illustrate concepts such as twodimensional motion, forces on an object, and images of the fringes that would be observed when using an interferometer. In each case, the user can interactively adjust critical parameters and observe the results. Figure 1 shows screenshots of several examples.

Each module is concluded with a section that enables students to check and revise their understanding. A short set of multiple-choice questions is provided for formative assessment. We generally provide three questions with four possible answers each. Upon answering the questions, students are given immediate feedback (Nicol \& Macfarlane-Dick, 2006; Marden, Ulman, Wilson \& Velan, 2013), purposely in the form of how many questions they correctly answered, rather than which answers were correct. This means that students cannot easily blindly guess until they obtain the correct answer, and instead are encouraged to further think through the question scenarios, and prompted to 
recognize the importance of going to the lecture to find out more. These questions are followed by a "before the lecture, you should be able to ..." checklist of essential learning goals. With a click, each bullet-point takes the user back to the relevant section of the module, making it easy for the student to review sections of particular value for him/herself (Herrington \& Oliver, 2000). In conjunction with the quick-check questions, the learning objectives checklist encourages review of key concepts in the module and provides a point of reflection.

Figure 1. Screenshots of sample simulations embedded in the modules. (a) Forces on a block sitting on an inclined surface; (b) Representation of wave motion; (c) Interference fringes in a Michelson Interferometer.
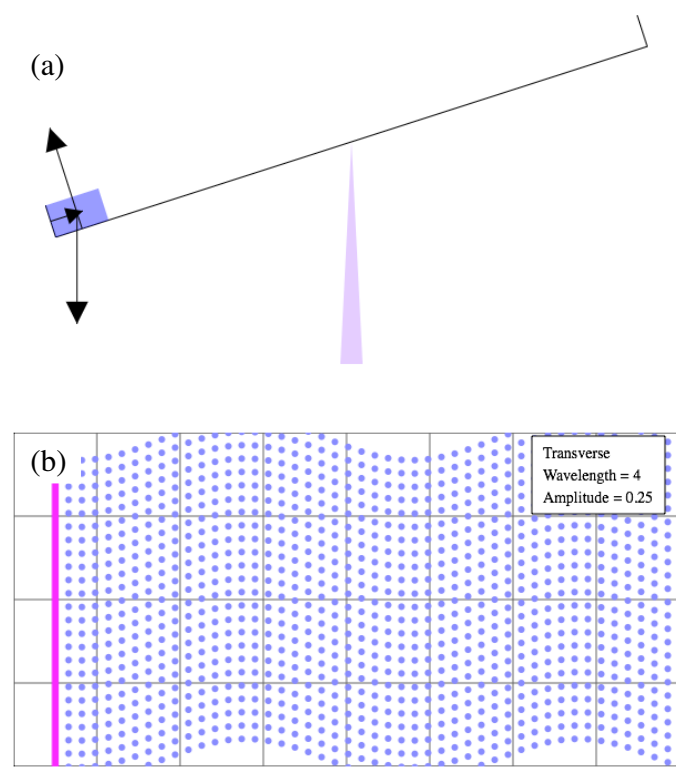

(c) Wavelength $=460 \mathrm{~nm}$

The effectiveness of the modules was assessed in a number of ways. Student use of the material was monitored, and feedback was obtained from students to gauge their attitudes to the approach. Students were surveyed before and after the implementation of 5MP modules, and focus groups were conducted by a person separate from the teaching team. The first-year students were polled in-class using "clickers." Statistics on access to the website were recorded, detailing information such as the number of times each page was visited, the number of unique visitors to a page, date and time of access, and the platform and browser used to view the page. Unsolicited feedback was also obtained through university administered course evaluation surveys. 
Such quantitative and qualitative data gathered during the gradual implementation of 5MP guided development of further modules. We also compared the performance over multiple years of the first-year classes who experienced full implementation of 5MP with previous offerings of the course.

\section{RESULTS AND DISCUSSION}

The outcomes of our implementation of 5MP are presented below. We refer specifically to three separate course offerings over one calendar year after 5MP was implemented, as summarized in Table 1, in which a detailed study was completed. We also discuss the continued use of the material in subsequent years.

Table 1. Details of the courses included in the study.

\begin{tabular}{lllll}
\hline Level/Semester & Course Name & Modules & Enrolment & $\begin{array}{c}\text { Number of Survey } \\
\text { Responses, N }\end{array}$ \\
\hline $\begin{array}{l}\text { Introductory } \\
\text { Semester 1 }\end{array}$ & The Physical Basis of Biological Systems & 9 & 194 & 105 \\
\hline $\begin{array}{l}\text { Introductory } \\
\text { Semester 2 }\end{array}$ & The Physical Basis of Biological Systems & 35 & 405 & 146 \\
\hline Core & Introduction to Fields in Physics & 3 & 65 & 36 \\
\hline
\end{tabular}

\section{Student surveys}

Student surveys were designed to explore how students perceived the 5MP and textbook material and how they made use of them. The surveys were completed in class towards the end of each course. Figure 2 shows the demographics of the survey respondents in each course. The first-year classes were dominated by students fresh out of high school, and had genders approximately balanced. The second-year course, a core physics course, was male dominated and had a slightly higher average age.

We asked students about their preferred method of accessing the online modules. As seen in Figure 3, this was roughly similar across all three implementations. Students made use of the variety of platforms available. Overall, desktop/laptop computers were used more commonly than mobile phones or tablet devices. Mobile usage was more significant in the introductory Semester 2 class with almost one third of the class indicating that they used a mobile device. Of mobile devices, about half were Apple devices and the rest were spread across other operating systems. The findings of a spread of platforms that needs to be catered for, and that students actually mostly look at these materials on a desktop/laptop, rather than on other, more portable devices, are similar to recent international results (deNoyelles \& Seilhamer, 2013). Our survey responses indicate that a computer was the preferred method of access when studying at home and a mobile device when elsewhere-"It depends on when I was accessing it. If I did the 5MP the night before, I'd use a computer, but if I was looking at it at Uni, I'd use my mobile phone." Reasons given for access preferences included ownership of a certain type of device, capability of accessing material when travelling (mobile), and screen size (computer). 
Figure 2. Demographics of students in each course. (a) Age; (b) Gender.
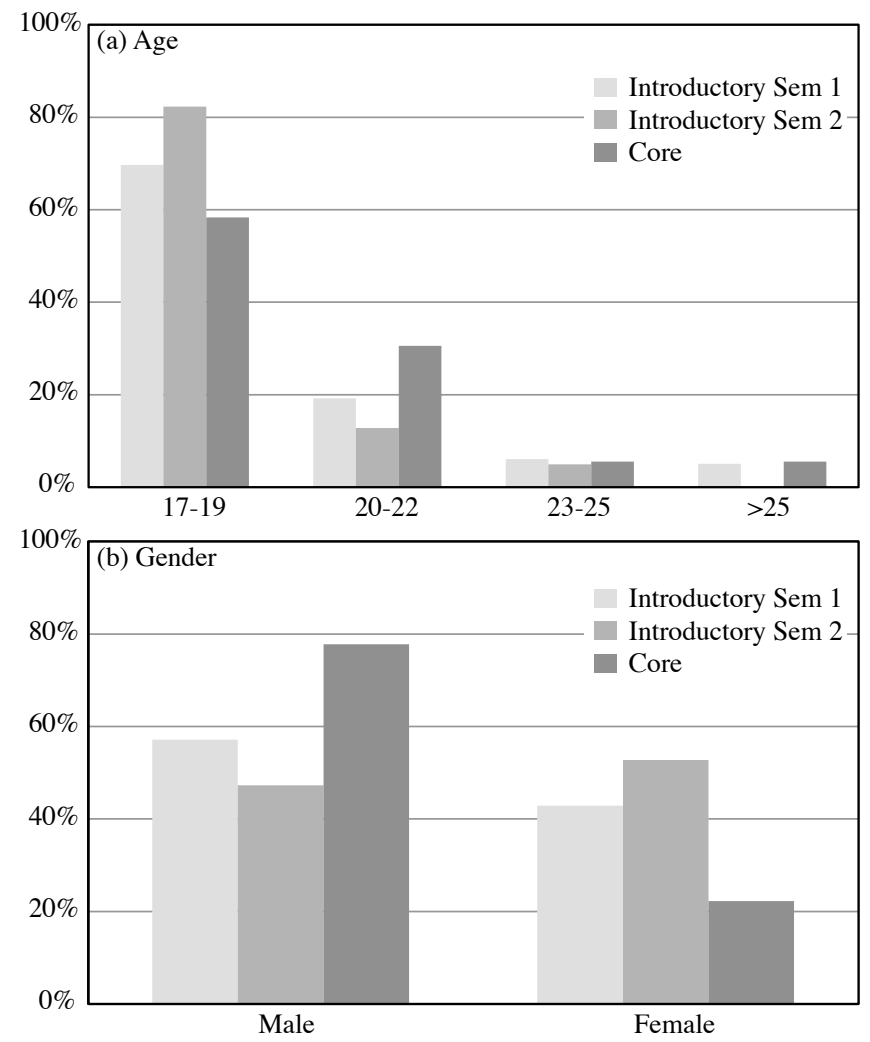

A major interest in developing this material was to encourage students to commit time to engaging with core material before class. Students were asked how regularly they prepared for class by using 5MP (when available), and how regularly they prepared with a textbook reading (always available). The success of the 5MP approach is clearly demonstrated in Figure 4. In each semester/course, $70 \%$ or more of respondents claimed that they frequently or always used the 5MP modules to prepare (when they were available). They reported higher rates of usage of 5MP than the textbook. Less than $40 \%$ of the first-year class and around $70 \%$ of the second-year class said that they frequently or always prepared for class with textbook reading. The preference for using $5 \mathrm{MP}$ is particularly evident in the introductory Semester 1 course where 5MP modules were used as pre-reading for about one quarter of the classes and the remainder were textbook readings.

Students were asked to comment on the relative advantages of 5MP and the textbook. In favor of 5MP, ease of access was noted: "it was more portable and easier to access." The advantages of electronic delivery were also highlighted-"multiple methods of delivering content" and "interactive and less text." 
Figure 3. Methods of accessing 5MP material. (a) By type of device; (b) By mobile operating system.
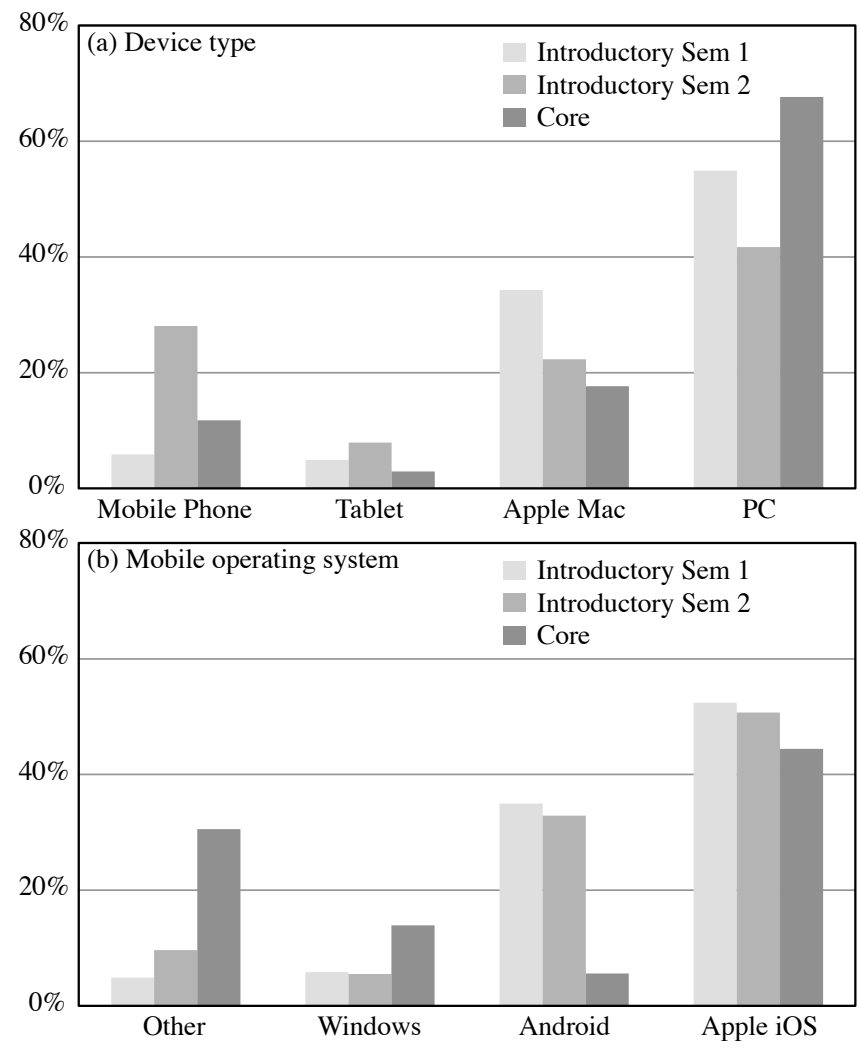

In contrast to introductory level students, textbook usage for the second-year core class was high. We propose several reasons for this difference. Firstly, the material in second year is more advanced, and students are unlikely to have prior knowledge of the material, so they need to commit considerable effort to understanding the novel content. Secondly, students in this course are generally physics majors and hence are more intrinsically motivated to learn the material. As an indicator of differences in study commitment, higher rates of never using the textbook and never using 5MP occur in the introductory course than in the core course. Lastly, the second-year students have already succeeded in completing one year of university physics which was taught in a style that required students to complete prescribed textbook reading before class, and so have already habituated to this type of responsibility.

It is apparent from the above that students were willing to commit time to using the 5MP modules; it is also obviously important that they benefit from committing that time to using the material. Students were surveyed on their perceptions of their level of preparedness for class after using the preparation materials. Figure 5 shows clearly that students more often felt prepared for class by using the $5 \mathrm{MP}$ modules than by reading the textbook. More than $70 \%$ of respondents in all courses always or frequently felt prepared for class using 5MP (more than 75\% for first-years). In comparison, around $20 \%$ of first-years and more than $40 \%$ of second-years always or frequently felt prepared for class using their respective textbooks. 
Figure 4. Responses to survey questions on pre-class preparation participation. (a) "(When 5MP was available) I used $5 M P$ to prepare for class"; (b) "(When 5MP was not available) I used the textbook to prepare for class."
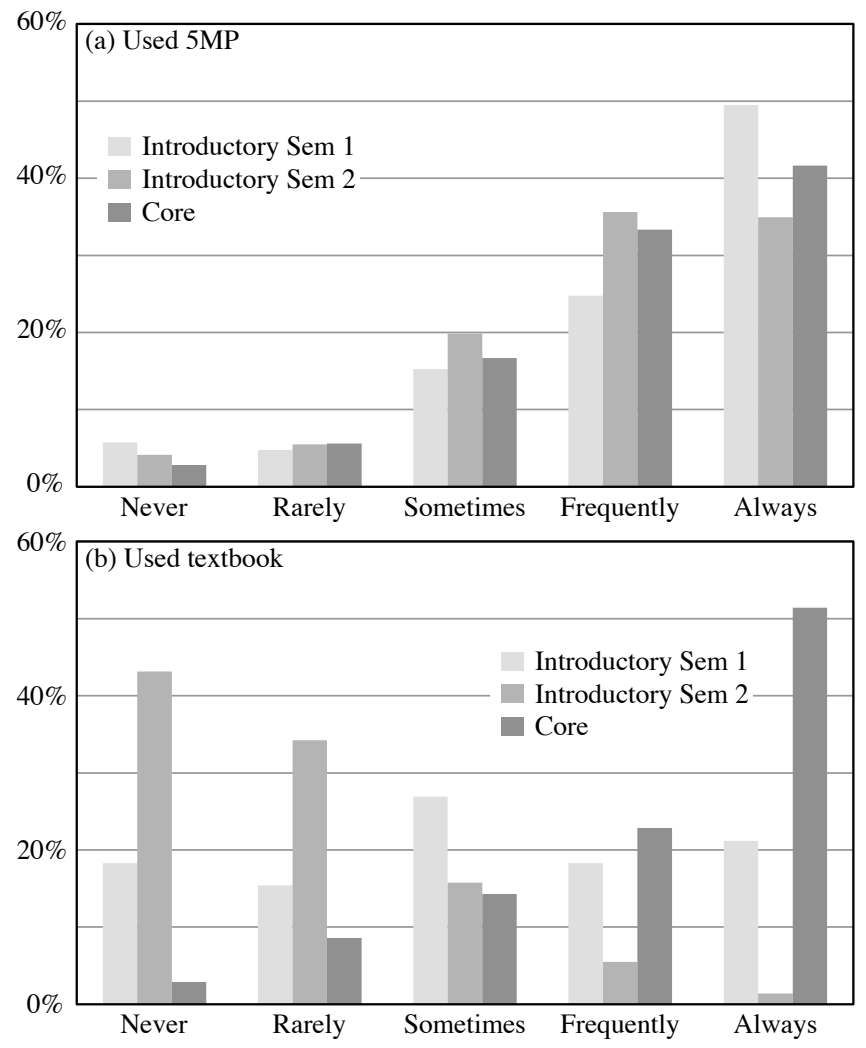

Another benefit discerned from surveys was that students found using the 5MP modules to be more enjoyable than reading a textbook. The distribution of survey responses on this aspect is shown in Figure 6. Students at both year levels enjoyed using 5MP, and they enjoyed using it much more than their textbooks-more than $60 \%$ of each cohort frequently or always enjoyed using 5MP; in comparison, less than $20 \%$ of each cohort frequently or always enjoyed using the relevant textbook.

A trend of decrease in positive student responses from the introductory classes in the two semesters can be attributed to the fact that, as many more modules were introduced, students were expected to use the modules for every lecture, not just a special few. In Semester 2 the modules were no longer a novelty. Going from Semester 1 to Semester 2, there is a drift in survey responses about 5MP use, enjoyment, and preparedness, from "always" to "frequently." The evidence that responses to 5MP remain positive with the humdrum of everyday adds confidence to the inherent quality of the 5MP experience. At the same time, use of the textbook fell dramatically, and the frequency of perceived benefit and enjoyment using the textbook also fell. This shows that the purpose of the textbook has changed.

We explored the impact of each type of component of a 5MP module-text and images, videos, simulations, and feedback questions. For each component, we asked students to indicate their agreement (on a five-point scale) with the statement that the component helped them in preparing for class. The results are shown in Figure 7. Students judged all of the various components of 5MP helpful in preparing for class. 
They most appreciated the text and images (more than about $85 \%$ in each course agree or strongly agree that these helped them prepare for class). While text and images may seem traditional, what students valued about these was their conciseness and assured relevance to the course.

Interactive simulations were seen as important. More than $75 \%$ of core course students agree or strongly agree that these helped them prepare for class. For the introductory course, the secondsemester students (for which many more simulations were created) were less convinced about their usefulness (more than $65 \%$ agree or strongly agree) than the first-semester students ( $85 \%$ agree or strongly agree). One issue worth considering here is that students are less certain about what to do with the simulations than other components. We are now providing more guidance on activities to undertake with the simulations.

Figure 5. Responses to survey questions on students' perception of being prepared for class. (a) "I felt prepared for class when using 5MP"; (b) "I felt prepared for class when using the textbook."
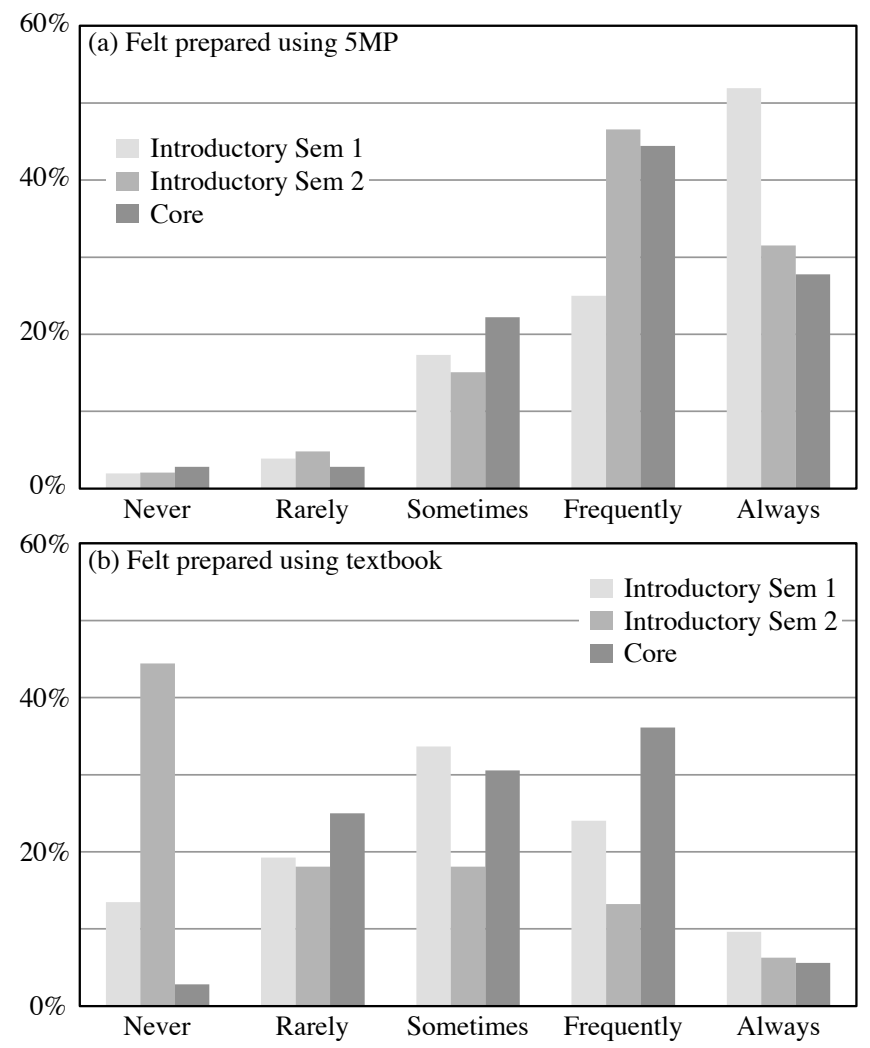

Videos were incorporated in the introductory course modules only. Here, more than $60 \%$ to $75 \%$ of students agreed they were useful. Many of the videos featured course staff explaining a concept or solving a problem. Despite staff concerns about the amateur nature of the videos produced, there was positive feedback from students who liked the fact that these featured their own course staff (rather than videos available over the internet). This valuing has also been observed independently by another academic producing webcasts of "live" physics problem-solving (Francis, 2013). 
Figure 6. Responses to survey questions on students' enjoyment of the pre-reading material. (a) "I enjoyed using 5MP"; (b) "I enjoyed using the textbook."

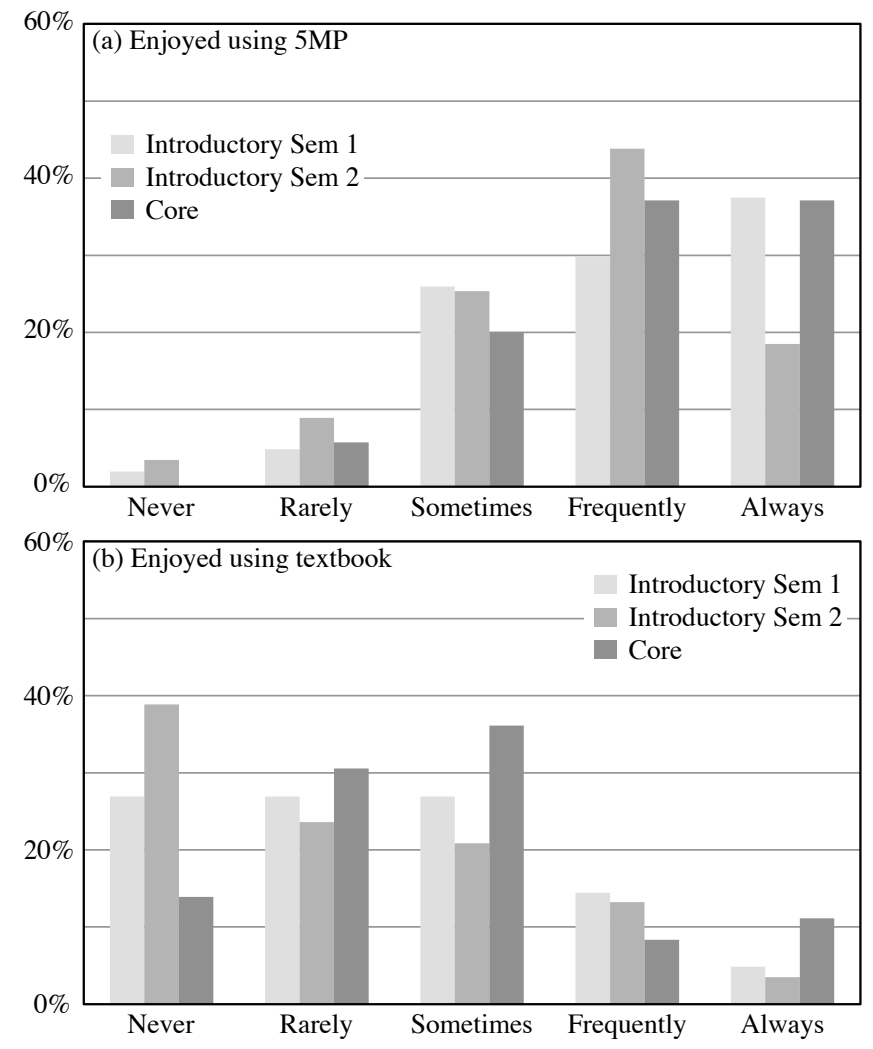

The introductory students found the self-check questions of great importance in their learning ( $85 \%$ agreed or strongly agreed that these questions helped). The core physics students also identified the questions as useful (about 55\%), but not to the same extent as the introductory students. We hypothesize that this difference between the cohorts in perceived value is because of the different sorts of students. Novice students in the introductory course can be either lost or on the right track, and not be sure which. These students are generally less certain of their abilities than core physics students and hence they find these questions useful to test themselves and provide feedback. In contrast, the more advanced students can better judge their state of learning themselves, and, being more confident in their level of understanding, find less benefit in these feedback questions.

In surveys, we asked students "How did Five Minute Physics help you learn?" Their freeresponse answers to this question were read in order to identify themes, and then the occurrence of each category was counted; the results of this thematic analysis are shown in Figure 8. The most-nominated helpful aspect was the direct relevance of the 5MP material to the content covered in class, exemplified by comments such as "(it) highlighted the main concepts covered in that lecture"; they valued "the specialization to this specific course rather than to broader physics concepts in general," ie: the more direct relevance than a textbook. This reaction, and perhaps a heightened attention to material whose relevance is assured, highlights a clear advantage to preparing one's own material for a class. Students frequently acknowledged that the preparation material provided familiarization and primed them for the learning experience of lectures, "read before lectures so I knew what was going on," recognizing that their learning was a process that occurred over a sequence of activities. Students appreciated the quality 
and accessibility of the explanations in the modules-"Explained things well," "Very clear and relatable concepts to help explain course material," "Showed practical applications of the theory." They welcomed the ease of access afforded by the use of technology and our format of small, separate chunks, "Portable," "Could be viewed in short bursts," "Easy to access." Students explicitly mentioned as valuable for their learning the interactive components of simulations and self-check questions that we had deliberately included because of their established usefulness to support learning.

Figure 7. Student responses when asked how each component of 5MP helped in preparing for class. (a) Text and images; (b) Videos; (c) Simulations; (d) Feedback questions.
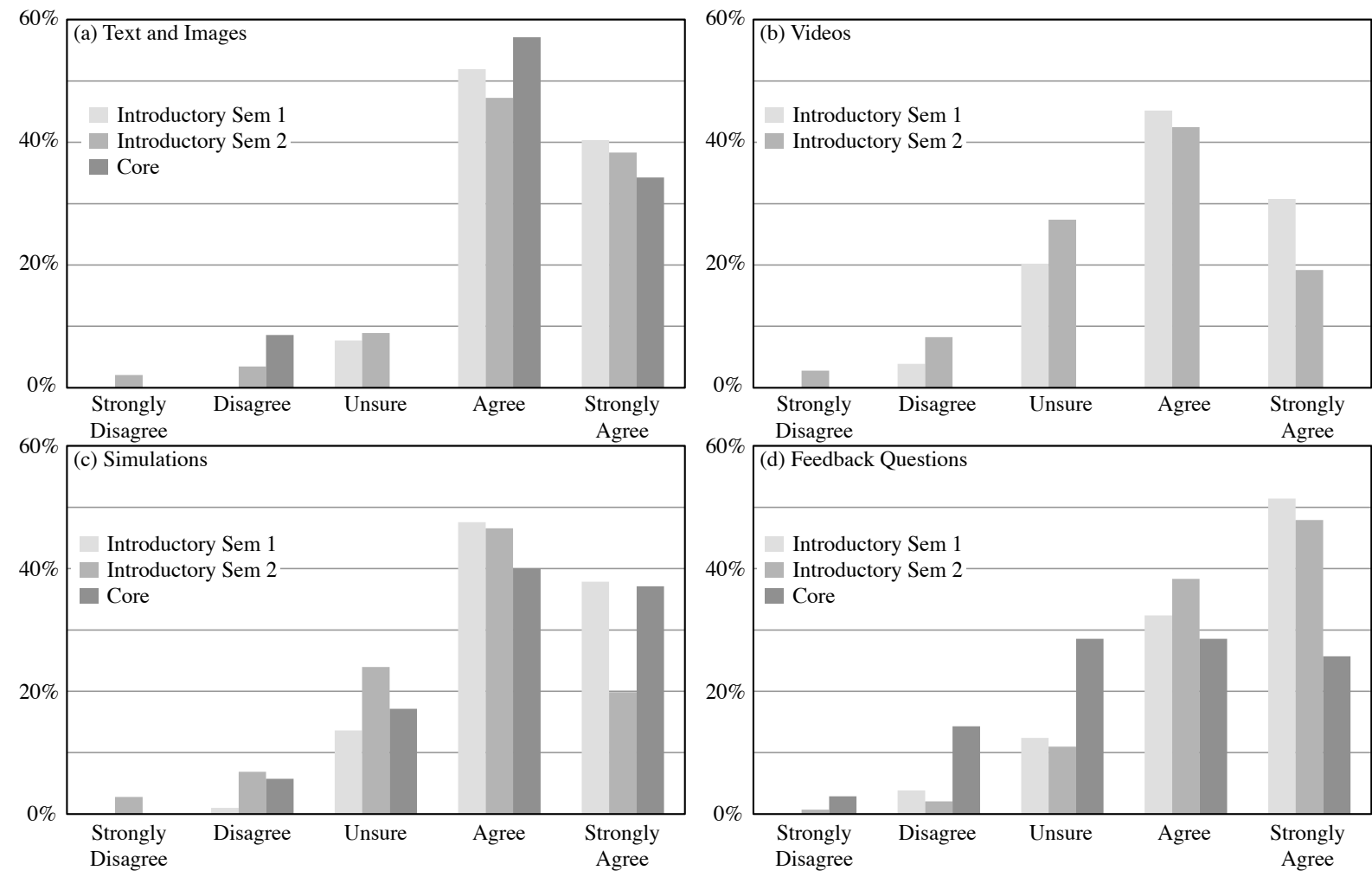

In-class (clicker) surveys

As well as using clickers for voting on multiple-choice concept questions, we have used clickers to operate surveys in class for the introductory course. Note that since this data is gathered from those students present at lectures, it is likely to have some bias towards more motivated or conscientious students. 
Figure 8. Themes in students' insights of how 5MP helped them learn.

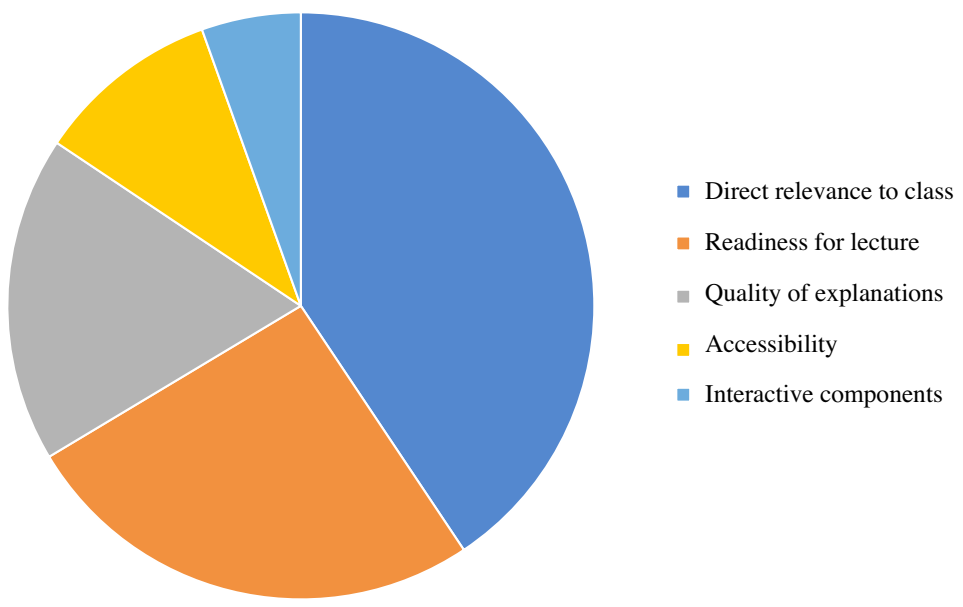

To gauge student participation in completing the "reading" before attending class, surveys have been done in the introductory class each semester since the second half of 2009. Students were asked to state whether they completed the reading before every lecture, regularly, occasionally or basically never ("What's the reading?"). The distribution of responses for each second-semester introductory level class since 2009 is presented in Table 2. (The student cohorts differ somewhat between Semesters 1 and 2.)

Table 2. Student self-reporting of regularity in completing pre-class reading.

\begin{tabular}{lllllllll}
\hline RESPONSE & 2009 & 2010 & 2011 & 2012 & 2013 & 2014 & 2015 & 2016 \\
\hline Before every lecture & $1 \%$ & $7 \%$ & $24 \%$ & $18 \%$ & $47 \%$ & $52 \%$ & $65 \%$ & $56 \%$ \\
\hline Regularly & $16 \%$ & $23 \%$ & $20 \%$ & $22 \%$ & $23 \%$ & $23 \%$ & $21 \%$ & $23 \%$ \\
\hline Occasionally & $32 \%$ & $40 \%$ & $21 \%$ & $23 \%$ & $16 \%$ & $11 \%$ & $9 \%$ & $13 \%$ \\
\hline "What's the reading?" & $51 \%$ & $30 \%$ & $35 \%$ & $37 \%$ & $14 \%$ & $14 \%$ & $5 \%$ & $8 \%$ \\
\hline Responses (N) & 77 & 136 & 227 & 199 & 292 & 269 & 231 & 172 \\
\hline
\end{tabular}

Over the timeframe of this study, there have been two significant changes to our approach to encourage students to complete the preparation for class. Firstly, since 2011, we have consistently used an assessable "reading" quiz in classes. Each lecture, students are given a multiple-choice question based on the relevant pre-class material, which they answer using their clickers. A bonus of up to $5 \%$ over the semester is awarded for correctly answering questions. According to the data shown in Table 2, this strategy had the effect of enhancing the frequency of preparation of those students who routinely completed the pre-class reading, but there was little change in the percentage of students who reported never completing the reading. Our second significant change was the introduction of 5MP. The table shows that this had a dramatic effect, with two-thirds of the class in 2013 stating that they regularly or always completed the reading, and only $14 \%$ stating that they never did the reading. These improvements have been maintained in subsequent years which have continued use of 5MP. We have taken the data presented in Table 2 and combined it with corresponding data from 
Semester 1 to generate a graphical representation of the impact of the interventions, shown in Figure 9. A score was allocated to each student's survey response about participation with zero corresponding to a student doing no reading, three to a student completing the reading before every lecture. An average of these scores was calculated to give a participation value for the class-with zero meaning that no students completed any reading and three meaning that all students completed the reading for every lecture. The results show a significant and persistent increase in the participation rate since the introduction of 5MP into the course.

Figure 9. Self-reported preparation participation for the introductory course. Assessed activities commenced from 2011 and $5 \mathrm{MP}$ was fully implemented from 2013.

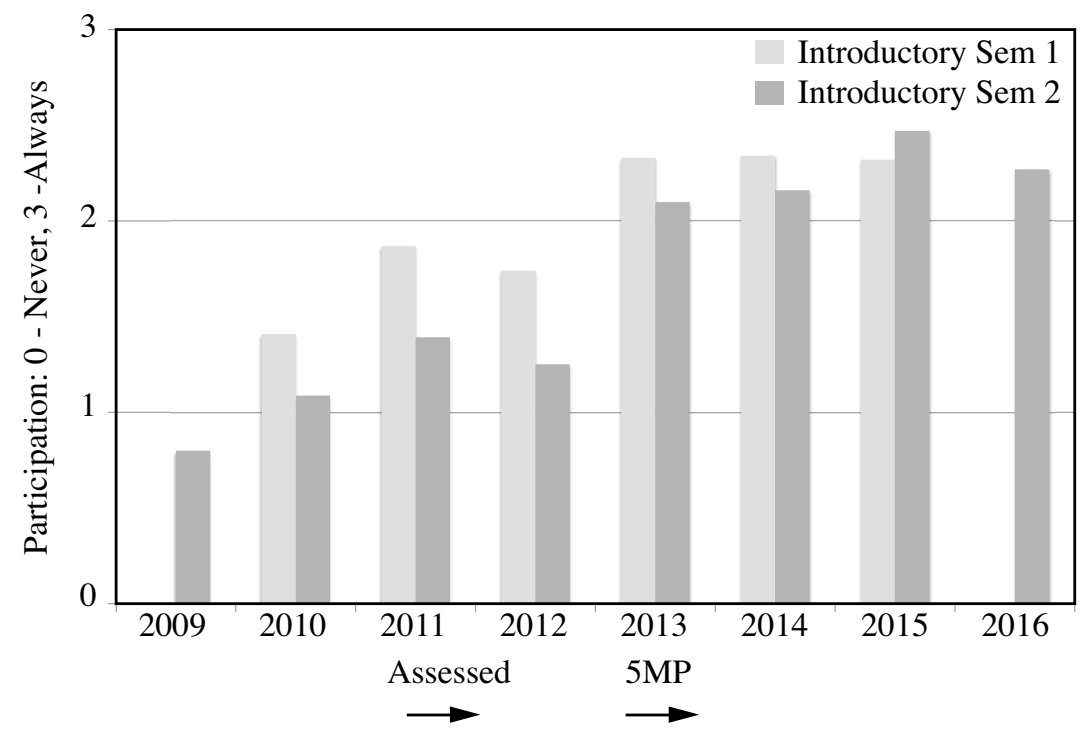

Clicker surveys were also used to gauge students' engagement in using the modules. Tables 3 and 4 show the distribution of students' responses when asked about their usage of simulation and video in particular modules. This data shows not only a spread in usage of the modules, as expected from students' self-reporting of usage habits, but also a range of engagement when using the modules, and with the particular components of simulation and video. In these instances, about a fifth of students hadn't used the relevant module before that lecture, about half admitted to incomplete use of the module, about a fifth engaged dutifully with the particular components, following prompts, and about a tenth used their own initiative, going beyond our initial expectations of how students would interact with the components; for example, doing their own experiments with the simulation.

\section{Access statistics}

We used online analytics to monitor usage of the 5MP website during the semester. Here we focus on the statistics for the full implementation in the second-semester, introductory course. The system records unique visits to the 5MP website ("Google," 2014).

In total, there were 19,200 unique visits to the 5MP website over the semester. With a course enrolment of 400, this corresponds to an average of 48 visits per student, compared to the 37 lectures (35 5MP modules) comprising the course. Averaged over the semester, there were around 205 unique visits per lecture day. This indicates a high level of usage. 
Table 3. Students' engagement in the Oscillation module, especially simulation component ( $N=225)$.

\begin{tabular}{lll}
\hline ENGAGEMENT & DESCRIPTOR & RESPONSE \\
\hline None & I didn't use the 5MP module & $23 \%$ \\
\hline Minimal & I glossed over everything in the module & $13 \%$ \\
\hline Partial & I watched the simulation but didn't play with it & $17 \%$ \\
& I fiddled with the simulation values for fun & $16 \%$ \\
\hline Full, as prompted & I tried to answer the questions posed with the simulation & $22 \%$ \\
\hline Self-directed & I did my own experiments with the simulation & $9 \%$ \\
\hline
\end{tabular}

Figure 10 displays the number of unique visitors per day throughout the semester. Use of the site shows a clear weekly cycle. Lectures were on Mondays, Tuesdays and Fridays and these were the three days that the site was most visited. Monday was the peak day, probably due to some students preparing for the lectures in close proximity on Monday at $12 \mathrm{pm}$ and Tuesday 9am. The periodic nature of the access data shows that students are habitually accessing the site and preparing for class either on the day of the class or the day (especially evening) before.

Table 4. Students' engagement in using the Heat Transfer module, especially video component ( $N=168)$.

\begin{tabular}{lll}
\hline ENGAGEMENT & DESCRIPTOR & RESPONSE \\
\hline None & I didn't use the 5MP module & $21 \%$ \\
\hline Minimal & I didn't watch the video & $33 \%$ \\
\hline Partial & I watched part of the video & $18 \%$ \\
\hline Full, as prompted & I watched all of the video & $21 \%$ \\
\hline Self-directed & I watched all of the video and replayed some sections & $7 \%$ \\
\hline
\end{tabular}

Usage also peaks with times of assessment, indicating that students used the modules as study aids. The timing of the two major assessment items for the course can be discerned in Figure 10. The mid-semester test (worth 15\% of the total assessment for the course) was held on Monday of Week 8. Close inspection shows that there is a significant increase in access on the day before the test. The final examination (worth 55\% of the course assessment) was held on Monday evening a week after the last class. There is regular access to the site in the week leading up to the exam. There is also very clear evidence of last-minute preparation for the examination-there were 300 unique visits (corresponding to three-quarters of the class) on the day of the examination.

Importantly, the analytics show that students spent an average time of around 10 minutes at the website each visit. This, combined with the number of daily visits to the site, would indicate that students are spending somewhere between 10 and 30 minutes online preparing for each lecture. This fact was consistent with the results of a question from an in-class survey conducted in recent years. 


\section{Student performance on assessment}

Over the period of our study, from when pre-class preparation was introduced in 2009, student performance in the introductory course has tended to improve. The grade distributions have changed, with a trend of more student performances qualifying for higher grades. The only significant change in criteria for awarding grades over this time has been a toughening of the requirement to pass (minimum performance on final exam) from 2011 onwards. Assessments that provide measures for these grades have been similar in type, balance, and difficulty. Most course learning and assessment activities, other than pre-class preparation, have been similar throughout this period. For the assessment tasks of tests during semester, tutorial worksheets and problem-solving assignments, variation in class performance over the period 2009-14 is never more than $10 \%$ of the marks available for each assessment type, and does not vary systematically.

Figure 10. Unique visits to the 5MP web-site per day by the introductory course students during one semester. There was a break from classes between semester weeks 10 and 11.

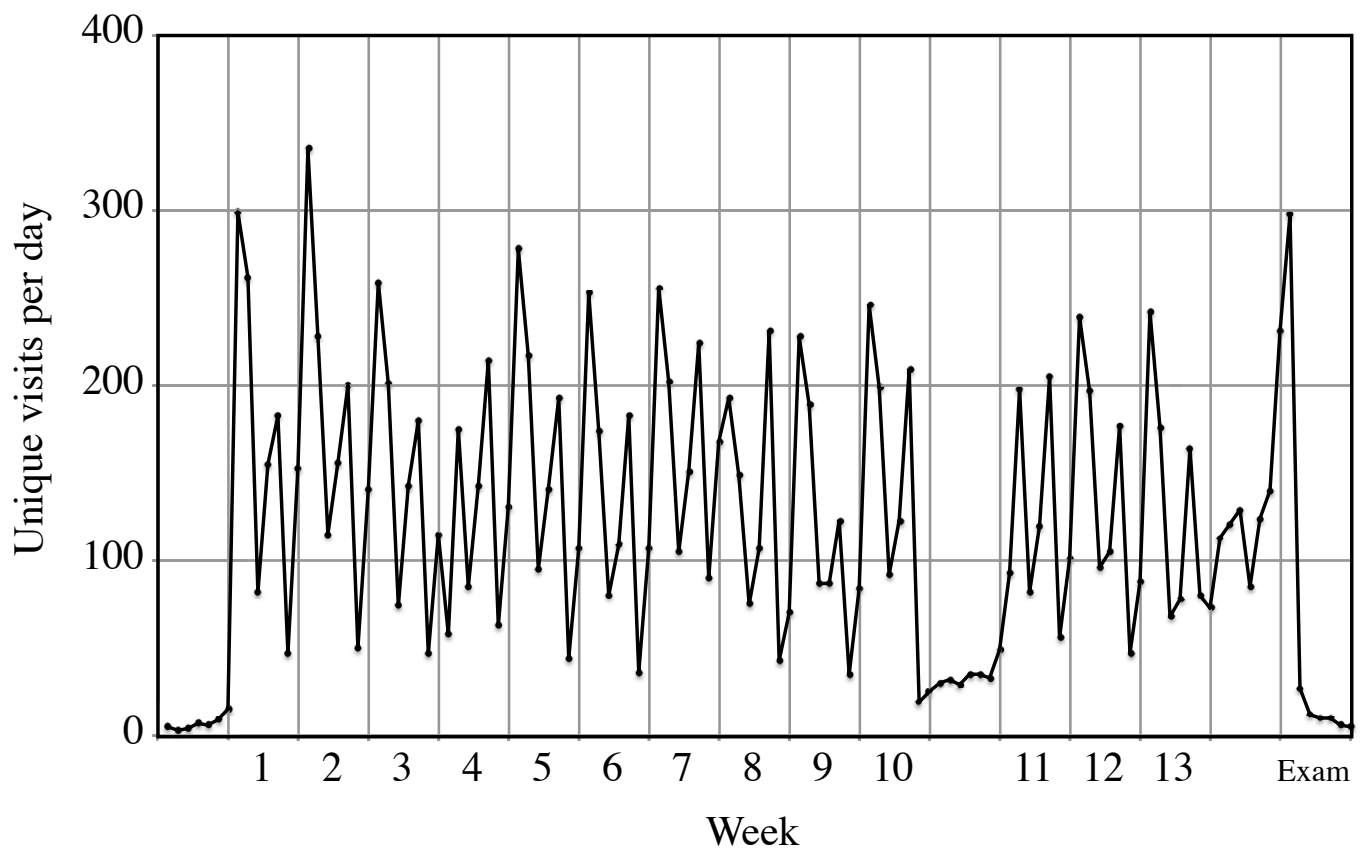

Figure 11 shows data for the assessment tasks that do contribute to improved overall performance including the reading quizzes on the pre-lecture preparation material and the final exams. Since assessment of pre-class preparation began to contribute to final grades for the course, there is a trend of improving performance on these reading quizzes. This correlates with improving trends in participation in reading quizzes, as measured by the proportion of the class enrolment who use clickers for reading quizzes (increasing from $74 \%$ in 2011 to consistently more than $90 \%$ since full implementation of 5MP in 2013). It also correlates with the marked improvement in self-reported rates of participation in pre-lecture preparation discussed earlier in this paper. Over the period of the study, there is a general trend of improvement in exam performance, measured by mean mark and median mark. The best class performances in both reading quiz and exam have occurred since the full implementation of 5MP. 
We can have confidence in the validity of comparison of performance from semester to semester because of consistency of the assessments. The reading quiz questions used each semester are the same or very similar. For the exams, the Semester 2 exams from 2009 to 2013 have been independently assessed to be of consistent difficulty (Scott, 2013; Rayner, 2013). Of course there are some variations in circumstances semester to semester that cannot be controlled for. For example, performance on a particular section of the Semester 1, 2013 exam, not related to 5MP material, was noticeably worse than any in recent history, and the result is an outlier in the data. The students enrolled in the course vary semester to semester. The Semester 2 offering is characterized by a significant cohort of students doing a particular degree, who have, on average, a better academic background than the rest of the class. The proportion of the enrolment that this cohort constitutes varies between roughly $25 \%$ and $35 \%$ over 2009-14, in a way that does not correlate with variations over time in performance on any type of course assessment. Therefore we can discount the possibility of the observed improvement in average class performance being simply due to cohort differences. We do have evidence of improved participation in class preparation, improved performance on assessment related to preparation activities, and improved performance on the final assessment task (exam). A causal link between these is easy to posit.

\section{Figure 11. Assessment results for the introductory class over recent years.}

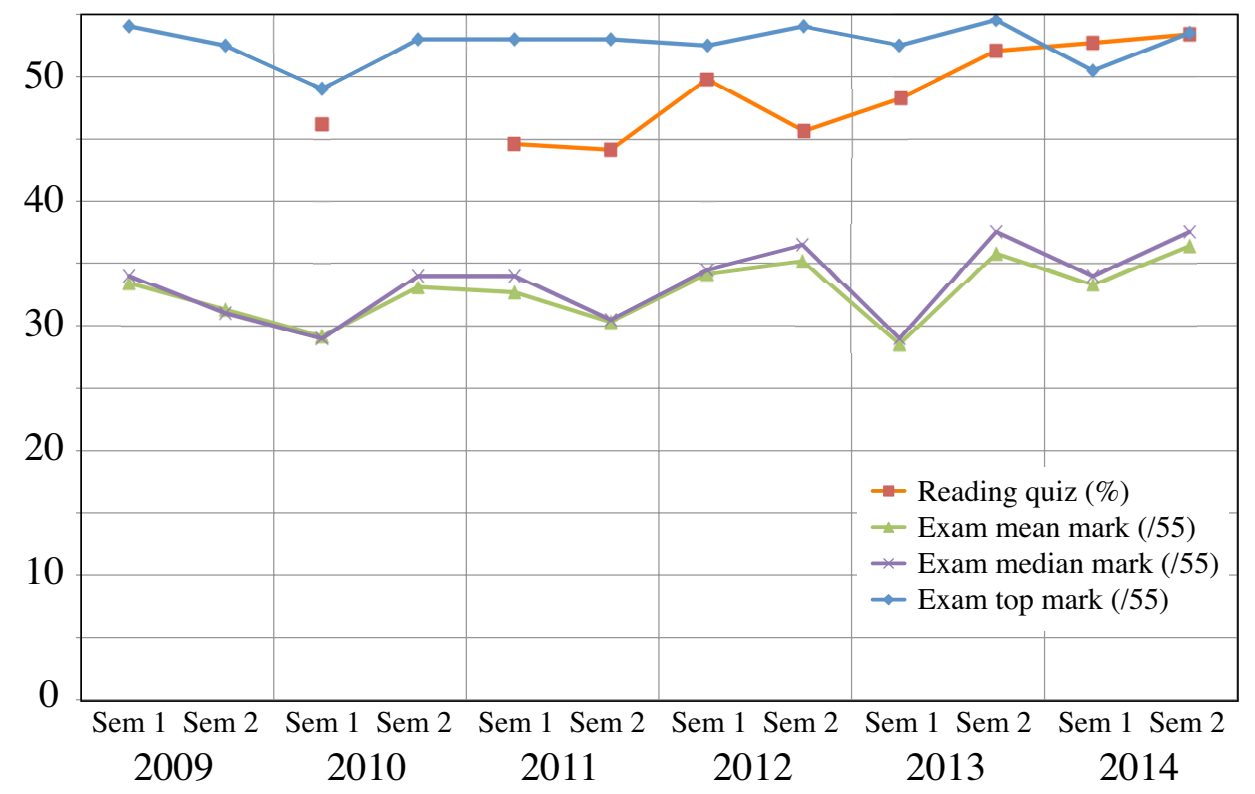

\section{Instructor perspective}

Although there was significant work involved in initially developing the e-learning modules, our experiences showed that this is well within the capabilities of a university teaching team with a moderate budget. This project moved from pilot to full implementation to uptake by others in rapid succession. We continue to develop the material in each of the courses. Ideally, we would like to incorporate several interactive elements in each module, including simulations and videos. Currently some of the modules are simply composed of text and images, with interactivity present only in true/false questions at the end of the module. Further development of these modules requires a time commitment not always available to busy academic staff. One way in which we have addressed this issue is by having undergraduate students work on them as projects in a third-year capstone course. These students have developed new 
simulations, assisted by academic staff, which will soon be incorporated into the relevant modules. We also continue to identify aspects of the material in which students demonstrate a poor understanding, and record short videos that address these issues.

The modules that have been developed are a valuable resource and continue to be used across the first-year and second-year courses despite some changes to the teaching teams involved. The positive response received from students has been particularly pleasing for the staff involved in developing the material. In university administered course evaluations conducted at the end of each semester there have been, and continue to be, many comments acknowledging the benefits of the approach that we have developed. Importantly, the material can be easily updated each semester with changes made in response to student feedback and/or perceived difficulties, and tailored to desired course experiences. It has been possible to extend the scheme to other courses, with minimal financial input, because of the modularity of structure of 5MP, and a template which we constructed during this project. We are collaborating with other academics to assist them to create their own modules. The scheme has been adopted by related disciplines of mathematics and chemistry at this university.

\section{CONCLUSION}

We have successfully addressed a widely-acknowledged issue in higher education: getting students to prepare for active-learning classes. We have developed and tested a set of online modules for students to use in preparing for class. The majority of students frequently or always completed the preparation when the material was supplied in this electronic format. This outcome is evidenced by inclass surveys and online access monitoring and has been persistent over a number of years. In contrast, far fewer of the students completed the preparation when only a traditional textbook reading was prescribed. 5MP has improved participation in preparing for class. Our surveying indicates that students in two significantly different courses preferred 5MP over a textbook. They felt better prepared for class when using the online material and they enjoyed using the online modules more than using the textbook. The online modules appear to have had a positive effect not only on student participation in pre-class preparation but also participation in in-class assessment related to that preparation, and performance on assessment. Improvement in student performance on consistent assessment tasks signifies that improved student learning is taking place.

Ease of access, on a variety of digital devices, significantly affected how likely students were to use the learning resources. Students incorporated use of these resources into their lifestyles. The more regular preparation that we achieved makes "flipped classroom" strategies more workable.

The various components of the online modules (text and images, videos, simulations, and feedback questions) were all considered valuable by students as learning experiences. These resources integrated interactive components such as self-check questions and interactive simulations that have been established as effective learning strategies. Accessibility of the content of the modules was a significant factor in helping students to learn. Students appreciated that the material that we had prepared was targeted towards their learning needs and featured their own teaching staff. This level of tailoring is feasible because of the editability of modular digital resources compared to a textbook. Furthermore, unlike a textbook, the online material can be updated even up until shortly before the class itself.

\section{ACKNOWLEDGEMENTS}

We gratefully acknowledge funding supplied by the University of Queensland to enable development and evaluation of these modules. We also acknowledge the research assistants Sam Peet, 
Sam Hinton, Amanda Smith, and Dr Cavin Talbot, undergraduate students Sam Hinton, Nurul Izzaty Yunus, Alex van Nunen, and Michael McClintock, programmer Trevor Daniels and graphic designer Tania Ryan who contributed to the project.

Ethics approval was given by the University of Queensland to allow publication of the data acquired in this project.

Timothy McIntyre is a teaching and research academic in the School of Mathematics and Physics at the University of Queensland, Australia. He has interests in the development and use of on-line interactive teaching approaches.

Margaret Wegener is a Teaching-Focused Senior Lecturer in Physics at the University of Queensland. As well as the scholarship of teaching and learning, she is deeply interested in the relationship between science and the arts.

Dominic McGrath is a Learning Designer in the Institute for Teaching and Learning Innovation at the University of Queensland. He is involved in the innovative use of technology and professional learning for educators.

\section{REFERENCES}

Adobe PhoneGap. (2014). About PhoneGap. [Website]. Retrieved February 3, 2014 from http://phonegap.com/

Bransford, J.D., Brown, A.L., \& Cocking R.R. (1999). How people learn: Brain, mind, experience, and school. Washington, DC: National Academy Press.

Christian, W. (2015). Physlets. [Website]. Retrieved September 16, 2015 from http://webphysics.davidson.edu/applets/applets.html.

Clark, R., \& Harrelson, G. (2002). Designing Instruction That Supports Cognitive Learning Processes. Journal Athletics Training 37(4), 152-159.

deNoyelles, A., Seilhamer, R. (2013). eTextbook access, usage, and beliefs: Implications for adoption in higher education. Journal of Applied Research in Higher Education 5(2), 189-201.

Educause. (2012). Things You Should Know about Flipped Classrooms. [PDF]. Retrieved December 13, 2013 from https://net.educause.edu/ir/library/pdf/ELI7081.pdf.

Francis, P. (2013). Examplecasts: The unreasonable effectiveness of webcast worked examples in introductory university physics. Australian Conference on Science and Mathematics Education, Australian National University, pp 136-141, ISBN 978-0-9871834-2-2.

Friedman, T. L. (2013). Revolution Hits the Universities, The New York Times, Retrieved December 13, 2013 from http://www.nytimes.com/2013/01/27/opinion/sunday/friedman-revolution-hits-theuniversities.html?_r=0.

Google. (2014). How Visits are calculated in Analytics. [Website]. Retrieved February 20, 2014 from https://support.google.com/analytics/answer/2731565.

Hake, R. (1998). Interactive-engagement vs. traditional methods: A six-thousand-student survey of mechanics test data for introductory physics courses. American Journal of Physics, 66, 65-74.

Head, K. (September 6, 2013). Lessons learned from a freshman-composition MOOC, The Chronicle of Higher Education. Retrieved December 13, 2013 from http://chronicle.com/blogs/wiredcampus /lessonslearned-from-a-freshman-composition-mooc/46337.

Herrington, J., \& Oliver, R. (2000). An instructional design framework for authentic learning environments. Educational Technology Research and Development 48(3), 23-48.

Kennedy, G., Dalgarno, B., Bennett, S. J., Judd, T., Gray, K., \& Waycott, J. (2008). Immigrants and natives: Investigating differences between staff and students' use of technology. In R. Atkinson and C. McBeath (Eds.), Annual Conference of the Australasian Society for Computers in Learning in Tertiary Education, (pp. 484-492). Melbourne, Australia: Deakin University.

Khan Academy. (2015). Khan Academy. [Website]. Retrieved September 7, 2015 from https://www.khanacademy.org/.

Lage, M., Platt, G., \& Treglia M. (2000) Inverting the classroom: A gateway to creating an inclusive learning environment. Journal of Economic Education 37(1), 30-43.

Lodge, J. (November 19, 2013). The failure of Udacity: Lessons on quality for future MOOCs, The Conversation. 
Retrieved December 13, 2013 from http://theconversation.com/the-failure-of-udacity-lessons-onquality-for-future-moocs-20416.

McGrath, D., Wegener, M.J., McIntyre, T. J., Savage, C., \& Williamson M. (2010). Student experiences of virtual reality: A case study in learning special relativity. American Journal of Physics 78(8), 862-868.

McIntyre, T., Wegener, M., McGrath, D., Kenny, E., \& Lenton, I. (2017). Five Minute Physics. [Website]. Retrieved May 9, 2017 from http://teaching.smp.uq.edu.au/fiveminutephysics/

McIntyre, T. (2017). SciMS [Website]. Retrieved May 9, 2017 from https://teaching.smp.uq.edu.au/scims/

McMullen, V. B. (2013). An Investigation of course requirements and student motivation to complete required readings. Mountain Rise, the International Journal for the Scholarship of Teaching and Learning, 8(1).

Mangan, K. (October 1, 2012). MOOC mania, The Chronicle of Higher Education. Retrieved December 13, 2013 from http://chronicle.com/article/Massive-Excitement-About/134678/.

Marden, N. Y., Ulman, L. G., Wilson, F. S., \& Velan, G. M. (2013). Online feedback assessments in physiology: Effects on students' learning experiences and outcomes. Advances in Physiology Education 37(2) 192-200.

Mazur, E. (2004). Peer Instruction: A User's Manual. Upper Saddle River: Prentice Hall.

Nicol, D. J., \& Macfarlane-Dick, D. (2006). Formative assessment and self-regulated learning: A model and seven principles of good feedback practice. Studies in Higher Education, 31(2), 199-218.

Phillips, B. J., \& Phillips, F. (2007) Sink or skim: Textbook reading behaviors of introductory accounting students. Issues in Accounting Education 22, 21-44.

Rayner, A. (2013). The University of Queensland, Personal Communication.

Scott, T. (2013). University of Otago, Personal Communication.

Wieman, C. E., Adams, W. K., \& Perkins, K. K. (2008). PhET: Simulations That Enhance Learning. Science 322(5902), 682-683.

Wolfe, J. (2015) PhysClips, [Website]. Retrieved September 16, 2015 from http://www.animations.physics.unsw.edu.au/.

\section{(c) (i)}

Copyright for the content of articles published in Teaching \& Learning Inquiryresides with the authors, and copyright for the publication layout resides with the journal. These copyright holders have agreed that this article should be available on open access under a Creative Commons Attribution License 4.0 International (https://creativecommons.org/licenses/by/4.0). The only constraint on reproduction and distribution, and the only role for copyright in this domain, should be to give authors control over the integrity of their work and the right to be properly acknowledged and cited, and to cite Teaching \& Learning Inquiry as the original place of publication. Readers are free to share these materials - as long as appropriate credit is given, a link to the license is provided, and any changes are indicated. 